\title{
Energy dissipation in brown adipose tissue: From mice to men.
}

Citation for published version (APA):

Vosselman, M. J., van Marken Lichtenbelt, W. D., \& Schrauwen, P. (2013). Energy dissipation in brown adipose tissue: From mice to men. Molecular and Cellular Endocrinology, 379(1-2), 43-50. https://doi.org/10.1016/j.mce.2013.04.017

Document status and date:

Published: 01/01/2013

DOI:

10.1016/j.mce.2013.04.017

Document Version:

Publisher's PDF, also known as Version of record

Document license:

Taverne

Please check the document version of this publication:

- A submitted manuscript is the version of the article upon submission and before peer-review. There can be important differences between the submitted version and the official published version of record.

People interested in the research are advised to contact the author for the final version of the publication, or visit the DOI to the publisher's website.

- The final author version and the galley proof are versions of the publication after peer review.

- The final published version features the final layout of the paper including the volume, issue and page numbers.

Link to publication

\footnotetext{
General rights rights.

- You may freely distribute the URL identifying the publication in the public portal. please follow below link for the End User Agreement:

www.umlib.nl/taverne-license

Take down policy

If you believe that this document breaches copyright please contact us at:

repository@maastrichtuniversity.nl

providing details and we will investigate your claim.
}

Copyright and moral rights for the publications made accessible in the public portal are retained by the authors and/or other copyright owners and it is a condition of accessing publications that users recognise and abide by the legal requirements associated with these

- Users may download and print one copy of any publication from the public portal for the purpose of private study or research.

- You may not further distribute the material or use it for any profit-making activity or commercial gain

If the publication is distributed under the terms of Article $25 \mathrm{fa}$ of the Dutch Copyright Act, indicated by the "Taverne" license above, 


\title{
Energy dissipation in brown adipose tissue: From mice to men
}

\author{
Maarten J. Vosselman, Wouter D. van Marken Lichtenbelt, Patrick Schrauwen* \\ Department of Human Biology, NUTRIM School for Nutrition, Toxicology and Metabolism, Maastricht University Medical Center+, Maastricht, The Netherlands
}

\section{A R T I C L E I N F O}

\section{Article history:}

Available online 28 April 2013

\section{Keywords:}

Brown adipose tissue

Beige adipocytes

UCP-1

Thermogenesis

Mitochondria

Obesity

\begin{abstract}
A B S T R A C T
In rodents, brown adipose tissue (BAT) is a metabolic organ that produces heat in response to cold and dietary intake through mitochondrial uncoupling. For long time, BAT was considered to be solely important in small mammals and infants, however recent studies have shown that BAT is also functional in adult humans. Interestingly, the presence and/or functionality of this thermogenic tissue is diminished in obese people, suggesting a link between human BAT and body weight regulation. In the last years, evidence has also emerged for the existence of adipocytes that may have an intermediate thermogenic phenotype between white and brown adipocytes, so called brite or beige adipocytes. Together, these findings have resulted in a renewed interested in (human) brown adipose tissue and pathways to increase the activity and recruitment of these thermogenic cells. Stimulating BAT hypertrophy and hyperplasia in humans could be a potential strategy to target obesity. Here we will review suggested pathways leading to BAT activation in humans, and discuss novel putative BAT activators in rodents into human perspective.
\end{abstract}

(C) 2013 Elsevier Ireland Ltd. All rights reserved.

\section{Introduction}

Brown adipose tissue (BAT) is a crucial organ in facultative thermogenesis (acute response) and has a great plasticity to respond to long-term changes (e.g. cold acclimation), known as adaptive thermogenesis. In addition to its important role in maintaining thermal homeostasis, BAT is likely to be involved in energy homeostasis as well, since ablation of the essential protein for heat production in BAT, uncoupling protein-1 (UCP-1), leads to an obese phenotype in mice housed at a thermoneutral temperature (Feldmann et al., 2009). Furthermore, it has been shown in mice that BAT is involved in plasma triglyceride clearance (Bartelt et al., 2011) and glucose homeostasis (Guerra et al., 2001; Gunawardana and Piston, 2012). This implies the important role of BAT in rodents to combat obesity and its related metabolic diseases, such as diabetes and cardiovascular disease. Interestingly, prospective studies have now demonstrated BAT to be present and functional in most (prevalence varying from 40\% to 100\%) young lean human adults by exposing them to cold (Cypess et al., 2012; Orava et al., 2011; Ouellet et al., 2012; Vijgen et al., 2011; Vosselman et al., 2012; Yoneshiro et al., 2012,

\footnotetext{
* Corresponding author. Address: Department of Human Biology, NUTRIM School for Nutrition, Toxicology and Metabolism, Maastricht University Medical Center, P.O. Box 616, 6200 MD Maastricht, The Netherlands. Tel.: +31 (0) 43 3881502; fax: +31 (0) 433670976 .

E-mail addresses: mj.vosselman@maastrichtuniversity.nl (M.J. Vosselman), markenlichtenbelt@maastrichtuniversity.nl (W.D. van Marken Lichtenbelt), p.schrauwen@maastrichtuniversity.nl (P. Schrauwen).
}

2011). Importantly, an inverse relationship has been shown between adiposity and BAT activity, indicating a relationship between BAT and obesity (Cypess et al., 2009; Saito et al., 2009; van Marken Lichtenbelt et al., 2009; Vijgen et al., 2011). In addition, there is evidence that BAT contributes to nonshivering thermogenesis (Orava et al., 2011; Ouellet et al., 2012; Vijgen et al., 2011; Yoneshiro et al., 2011), although this relationship has not always been found (van Marken Lichtenbelt et al., 2009; Vosselman et al., 2012). It has been estimated that fully activated BAT in humans can contribute to $5 \%$ of the basal metabolic rate (van Marken Lichtenbelt and Schrauwen, 2011). This means that stimulation of BAT can have an impact on long-term energy balance and thus body weight, however only when other factors (e.g. food intake) remain stable (Christiansen and Garby, 2002). Maybe more important, stimulation of BAT could be supportive in body weight maintenance. Therefore, finding strategies to increase BAT activity and recruitment in humans could be important to combat obesity and its related chronic metabolic diseases. Currently, much effort is being put in finding ways to increase BAT thermogenesis and the recruitment of brown adipocytes in rodents. The recent discovery of the so-called brown-in-white (brite) or beige adipocytes has further increased the interest in BAT. Increased "browning" of WAT could be an attractive way to induce weight loss. It is therefore important to find strategies to increase the thermogenic machinery of BAT and brown-like tissues in humans. This review will provide an overview of the most promising pathways to increase BAT activity and recruitment in humans. 


\section{Brown, beige and white adipose tissue}

\subsection{Brown versus white adipose tissue}

In rodents, brown adipose tissue is clearly distinguishable from white adipose tissue, since it is richly innervated by the sympathetic nervous system (SNS), is highly vascularized, and contains brown adipocytes with several small lipid vacuoles and many large mitochondria (Frontini and Cinti, 2010). Unique for the brown adipocyte is the protein UCP-1 located in the inner mitochondrial membrane, which allows protons in the intermembrane space to re-enter the mitochondrial matrix without generating ATP, ultimately resulting in heat production.

White and brown adipose tissue in mice can be found in distinctive or classical (i.e. pure white or pure brown) depots (Fig. 1A). All these depots have been characterized by genetic markers, and have a distinct genetic profile that probably determines its function (Waldén et al., 2012). Note that these adipose tissue depots sometimes are also viewed as one organ, known as the adipose organ (Cinti, 2001).

The largest BAT depot found in mice, iBAT, is predominantly found in human neonates and infants, and then gradually disappears after childhood (Heaton, 1972) and is rarely seen in human adults (Fig. 1B). In adult humans, BAT ( $\left[{ }^{18} \mathrm{~F}\right] \mathrm{FDG}$-uptake) is often found in the neck, the mediastinum (para-aortic), and above the kidney (suprarenal), which is comparable to some BAT depots (cBAT, mBAT, prBAT) in mice. Furthermore, BAT in humans is located along the spinal cord, in the axillary and abdominal region (suprarenal and perihepatic), and sometimes in areas such as the abdominal wall and acromial-clavicular area. The most prominent and most reported BAT depot in humans is supraclavicular BAT, which has not been found as a distinct depot in mice.

\subsection{Brown like cells in white adipose tissue}

In addition to classical BAT, a distinct type of adipocytes has been found within WAT depots, the so-called brite (Petrovic et al., 2010) or beige adipocytes (Wu et al., 2012). However, this is still under dispute as white fat cells may differentiate into brown fat cells (Cinti, 2002). At present, no consensus on the terminology of these brown-like white adipocytes has been reached, and is urgently awaited. However, for sake of clarity we will refer to these cells as beige adipocytes in the remainder of this review. These beige adipocytes can appear within WAT depots after long-term adrenergic stimulation and cold exposure, and especially appear in the inguinal depot. In the basal state, these beige cells resemble the unilocular white adipocytes, whereas upon stimulation these cells obtain a more brown like phenotype. Furthermore, these cells do not express the myogenic markers nor the brown adipocyte specific markers Zic1, Lhx8, Meox2, and PRDM16 (Petrovic et al., 2010), but express specific markers as well (e.g. Hoxc9) (Waldén et al., 2012). Interestingly, Wu et al. (2012) were able to isolate brown-like cells from the subcutaneous (inguinal) adipose depot and found a distinct pool of progenitors giving rise to these socalled beige cell lines. Linkage of the expressed genes after microarray analysis in these cell lines revealed that beige adipocytes are
A

C

\begin{tabular}{|l|l|}
\hline Rodent BAT and beige depots & Specific markers \\
\hline Classical BAT & $\begin{array}{l}\text { Zic1, Lhx8 (Waldén et al., 2012; } \\
\text { Sharp et al., 2012) } \\
\text { Ebf3, Eva1, Fbxo31 (Wu et al., 2012) }\end{array}$ \\
\hline Beige depots (cWAT, rWAT, iWAT) & $\begin{array}{l}\text { Hoxc9, Shox2 (Waldén et al., 2012) } \\
\text { Tbx1, Tmem26, CD137 (Wu et al., } \\
\text { 2012) } \\
\text { Fgf21, Car4, Cited1 (Sharp et. al, } \\
2012)\end{array}$ \\
\hline
\end{tabular}

B

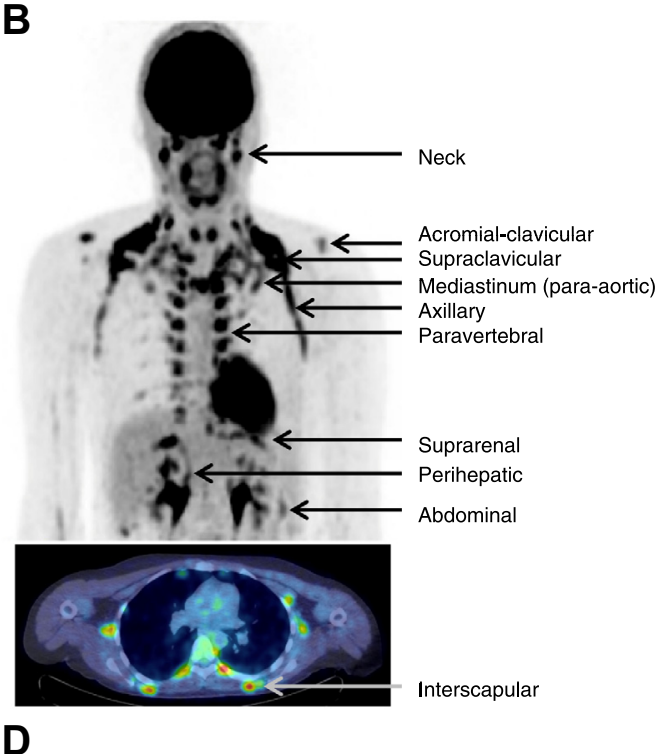

\begin{tabular}{|c|c|}
\hline Human BAT and beige depots & Specific markers \\
\hline Classical BAT: not (yet) identified & - \\
\hline 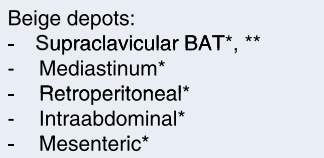 & $\begin{array}{l}\text { Tmem26, CD137, Tbx1 (Wu et al., } \\
\text { 2012, only supraclavicular) } \\
\text { Hoxc8, Hoxc9, Cited1, Fgf21, CD137, } \\
\text { Tmem26 (Sharp et al., 2012, all } \\
\text { depots) }\end{array}$ \\
\hline
\end{tabular}

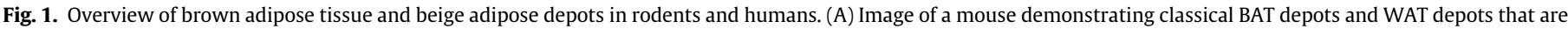

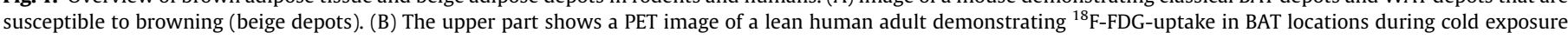

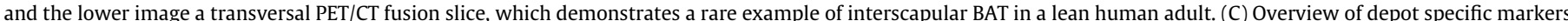

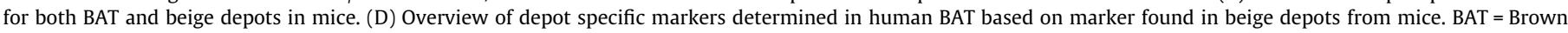
adipose tissue, WAT = White adipose tissue. ${ }^{*}$ Measured in children (Sharp et al., 2012), ${ }^{* *}$ Measured in human adults (Wu et al., 2012). 
identical, but not similar, to classical brown adipocytes. These beige adipocytes were characterized by unique genetic markers, such as CD137, Tmem26, and Tbx1, and did not contain unique BAT markers such as Ebf3, Eva1 and Fbxo31 (Fig. 1C). Furthermore, they found that unstimulated beige cells resemble white adipocytes since they have similar low expression of the brown adipocyte markers UCP-1, Cidea, and Cox7a1. However, upon cAMP stimulation absolute levels of UCP-1 mRNA and respiratory capacity were comparable to classical brown adipocytes. In coherence with this, Petrovic et al. (2010) showed beige cell recruitment in the inguinal depot, and that even the purest WAT depot (epidydimal) contains preadicpocytes that can be induced to functional beige adipocytes. Again, a low basal UCP-1 expression was found during baseline conditions, however, after rosiglitazone (PPAR $\gamma$ activator) treatment beige cells increased UCP-1 expression and demonstrated many features of the classical brown adipocytes. Moreover, oxygen consumption increased after treating these cells with norepinephrine. In conclusion, it is clear that beige adipocytes are molecular and developmentally different from classical brown adipocytes, however, after stimulation these cells show comparable thermogenic potential.

\subsection{Type of brown adipocytes in humans}

Do humans have brown, beige or both types of adipocytes? Studies measuring BAT via FDG-PET/CT cannot determine the type of BAT, as it merely measures glucose uptake. However, biopsies from the supraclavicular region (Virtanen et al., 2009) and the perithyroid region (Zingaretti et al., 2009) have already demonstrated a mixture of both white and brown adipocytes, and showed that brown adipocytes occur as islands within WAT. The clearly brown colored depots as found in mice, have not (yet) been found in humans. Interestingly, a recent study has examined several adipose depots in 13 post-mortem children (aged between 3 days and 18 years) and also found the brown like cells dispersed within WAT (Sharp et al., 2012). These brown adipocyte islands were located in the subcutaneous supraclavicular areas, posterior mediastinum, retroperitoneal, intraabdominal, and mesenteric depots.

In the study by Wu et al. (2012), human adipose tissue biopsies (both WAT and BAT) from the supraclavicular area were analyzed for gene expression. Interestingly, we found increased mRNA expression of the genes that were characteristic for beige cells (CD137, Tmem26, Tbx1) and not classical murine BAT (Ebf3, Eva1, Fbxo31) (Fig. 1D). In addition, we also performed immunohistochemistry to identify the beige marker proteins (CD137 and Tmem26), and found positive staining for both proteins in the UCP-1 positive cells. Thus, human BAT from the supraclavicular area in adults has beige characteristics. In the study by Sharp et al. (2012), total RNA was isolated from the BAT depots from post-mortem children, and interestingly, all BAT depots expressed beige-cell selective genes and no classical brown fat-selective genes (Fig. 1D). They found that these BAT depots correlated well with the expression of brown fat genes such as PGC1 $\alpha$ and PRDM16, and with beige-cell genes (e.g. Cited1), however not with classical BAT genes (e.g. Zic1) (Sharp et al., 2012). These findings thus indicate that human BAT may be composed of mainly beige adipocytes.

\section{BAT physiology}

Crucial in activating BAT thermogenesis is the sympathetic nervous system (SNS). Furthermore, the thermogenic capacity of BAT is dependent on the thyroid hormone axis as well. After sympathetic stimulation, norepinephrine (NE) is released at the nerve endings activating the adrenergic receptors on the brown adipo- cytes. This leads to increased cAMP levels activating protein kinase A (PKA), which has both acute and chronic effects on BAT. The acute response of PKA is to increase lipolysis leading to increased cytosolic FFA levels. These FFA's are essential for mitochondrial energy dissipation, as they are both used as substrates and to activate UCP-1 in the inner mitochondrial membrane. This acute effect increases UCP-1 activity within seconds. On the other hand, prolonged stimulation of BAT for hours and days will result in increased amounts of UCP-1 protein, mitochondrial biogenesis, and both hyperplasia and hypertrophy of BAT (Lowell and Spiegelman, 2000). The thyroid hormone works synergistic with NE and is required to generate the full thermogenic response (Silva, 2006). Crucial is the enzyme type II iodothyronine deiodinase (D2, which can transform the inactive prohormone thyroxine (T4) into the bioactive hormone triiodothyronine (T3).

In contrast to the extensive knowledge in rodents, the regulation and activation of human BAT is still fairly unknown. However, both the SNS and the thyroid axis are thought to be crucial in activation of BAT in humans too. For instance, patients with pheochromocytoma, who have elevated plasma catecholamine levels due to a catecholamine-secreting tumor in de adrenal gland, had high rates of $\left[{ }^{18} \mathrm{~F}\right] \mathrm{FDG}$-uptake in BAT in the basal state (Hadi et al., 2007; Joshi and Lele, 2012; Kuji et al., 2008; Yamaga et al., 2008), which disappeared after resection of the tumor (Hadi et al., 2007; Yamaga et al., 2008). Thus, high systemic levels of NE can activate human BAT, indicating a role for the adrenergic part of the SNS. In support, inhibition of $\beta$-adrenergic receptors with propranolol diminished $\left[{ }^{18} \mathrm{~F}\right] \mathrm{FDG}$-uptake in the supraclavicular BAT during room temperature (Parysow et al., 2007; Soderlund et al., 2007). In 2009, anatomical evidence for the SNS involvement in BAT was found, as BAT biopsies from the perithyroid (Zingaretti et al., 2009) and supraclavicular region (Virtanen et al., 2009) demonstrated sympathetic innervation and mRNA expression of the $\beta_{3}$ adrenergic receptor respectively. Finally, disruption of the sympathetic fibers completely abolished $\left[{ }^{18} \mathrm{~F}\right] \mathrm{FDG}$-uptake in BAT in a patient with the Horner Syndrome (deficiency of sympathetic activity) (Lebron et al., 2010). With respect to the thyroid hormone axis, it is known from patients that thyroid hormone replacement has significant effects on resting energy expenditure (al-Adsani et al., 1997). It has also been shown that elevated levels of thyroid hormones are able to increase mitochondrial uncoupling in skeletal muscle (Lebon, 2001; Mitchell et al., 2010). Although these results may suggest that thyroid hormone also plays a role in activation of BAT, evidence for such a role in humans has so far not been demonstrated.

\section{Known BAT activators in humans}

Since the discovery of functional BAT in adult humans, some studies have examined possible routes to activate BAT in humans, which will be discussed here.

\subsection{Cold exposure and acclimatization}

Currently, the strategy for which most evidence has been gathered to activate BAT in humans is cold exposure. In our cold exposure experiments we applied a personalized cooling protocol in which we decreased ambient temperature until shivering occurred $\left(16-17^{\circ} \mathrm{C}\right)$ and then increased temperature slightly again. At these mild cold temperatures, cold-induced thermogenesis levels in young lean male adults were observed between 5\% and 30\% (van Marken Lichtenbelt et al., 2009; Vosselman et al., 2012). Brown adipose tissue was present in all individuals, however the activity level of BAT did not correlate to cold-induced thermogenesis. Other studies did find a relationship between BAT presence and/or activ- 
ity and cold-induced thermogenesis (Orava et al., 2011; Ouellet et al., 2012; Vijgen et al., 2012, 2011; Yoneshiro et al., 2011). Cold exposure likely increased BAT activity via the SNS as shown by increased plasma NE levels during cold exposure (Orava et al., 2011; Vosselman et al., 2012).

It is well known from animal studies that long-term cold exposure leads to BAT recruitment in both BAT and WAT depots (Young et al., 1984). A cold acclimation study in humans in 1961 demonstrated that long-term cold exposure was effective to increase cold-induced thermogenesis in man, with a decrease in shivering, indicating a potential role for BAT (Davis, 1961). Preliminary results from our lab confirm this adaptive response to cold acclimation as both cold-induced (non-shivering) thermogenesis and BAT activity increase (unpublished results).

\subsection{Isoprenaline and ephedrine}

Rodent studies have clearly demonstrated that BAT can be activated (acute) and recruited (chronic) upon adrenergic receptor agonist treatment. Recently, three studies measured the effect of adrenergic stimulation on BAT activity in human adults. We measured BAT activity in lean human adults during infusion of the nonselective $\beta$-adrenergic agonist isoprenaline, and compared this to cold exposure (Vosselman et al., 2012). Isoprenaline infusion increased energy expenditure with $20 \%$ comparable to levels during cold exposure (17\%). Surprisingly, nine out of ten subjects showed no BAT activity during isoprenaline infusion, whereas cold exposure increased BAT activity in all subjects. Cypess et al. (2012) studied the effects of ephedrine ( $1 \mathrm{mg} / \mathrm{kg}$ ), which is a sympathomimetic drug activating $\beta$-adrenergic receptors directly and indirectly by enhancing NE release from the sympathetic terminals, on BAT activity and compared this with cold exposure and placebo. In coherence with our results (Vosselman et al., 2012), ephedrine did not result in BAT activity measured by FDG-PET/CT measurements, whereas cold exposure activated BAT in all subjects (Cypess et al., 2012). However, a recent study using higher dosages of ephedrine $(2.5 \mathrm{mg} / \mathrm{kg})$ did find increased BAT activity in six out of nine lean human adults, however not in obese subjects (Carey et al., 2013). This is the first study that showed that pharmacological treatment of BAT in humans is possible. The activity level of BAT was still 4-fold lower than observed during cold exposure. The explanation for the lack of effect of systemic adrenergic stimulation on BAT activation is likely that the concentrations of NE reached at the brown adipocyte cell surface during central stimulation (e.g. cold exposure) are higher than systemically reached by the sympathomimetics used in these studies. Thus, pharmacological stimulation of BAT is possible, however high dosages are required. A major burden of very high levels of sympathomimetic drugs is the cardiovascular load induced by adrenergic agonists. All three studies observed increased blood pressure and heart rate levels, with the highest increase in systolic blood pressure $(45 \mathrm{mmHg})$ measured in the study by Carey et al. (2013).

\subsection{Capsinoids}

Another route to activate BAT via the SNS is via ingestion of certain food components. One such component are the capsinoids (non-pungent capsaicin analogs), the active compound found in chili pepper, which is known to increase BAT activity in rodents (Kawabata et al., 2009), and RMR in humans (Whiting et al., 2012), although this has not been consistenly shown (among others: Galgani and Ravussin, 2010). A recent study showed that capsinoids could be effective in activating BAT in humans (Yoneshiro et al., 2012), without inducing unwanted side-effects. Although they did not directly measure the effect of capsinoid intake on BAT activity, they found that subjects with BAT (based on cold
PET-CT) showed a higher increase in energy expenditure upon capsinoid intake compared to subjects without BAT. The proposed mechanism is that capsinoids activate the transient receptor potential channel 1 (TRPV1) located in the upper digestive tract leading to increased sympathetic nerve activity to BAT, as demonstrated in interscapular BAT in rats (Ono et al., 2011). Direct evidence for the effect of capsinoids on BAT in humans is needed to draw definite conclusions. Furthermore, whether long-term administration of these bioactive compounds can induce weight loss via BAT remains to be studied.

\subsection{Insulin}

Another way to induce glucose uptake in BAT is via insulin (Orava et al., 2011). In this study, insulin infusion (hyperinsulinemic euglycemia) was compared with cold exposure on BAT glucose uptake and perfusion. They showed that insulin increased $\left[{ }^{18} \mathrm{~F}\right]$ FDG-uptake in BAT to similar levels as in skeletal muscle, and much higher than in WAT. This was most likely due to the high expression of GLUT4 in BAT compared to WAT. However, the increased $\left[{ }^{18} \mathrm{~F}\right] \mathrm{FDG}$-uptake in BAT was not accompanied by increased perfusion, suggesting that glucose is solely transported in BAT without concomitant thermogenesis taking place. Since insulin leads to high glucose uptake in BAT, it would be interesting to measure whether BAT is involved in glucose uptake, and possibly thermogenesis, in the postprandial state as well. It is known from rodent studies that single meals can activate BAT, which could be due to insulin release (Cannon and Nedergaard, 2004).

\section{Novel putative BAT activators}

Next to the known activators of BAT as described above, novel findings in mainly rodent studies hint towards other potentially important activators of BAT. The focus of this paragraph will be on the hormones irisin (released by muscle) and the natriuretic peptides (released by heart). We have chosen for these hormones as they are released under physiological conditions (exercise and cardiac stress), and because there is already indirect evidence of these activators in humans. For information on the other potential BAT activators we would like to refer to other reviews (Whittle, 2012; Whittle and Vidal-Puig, 2012).

\subsection{Exercise and brown adipose tissue: irisin}

Exercise is well known for its beneficial effects on systemic metabolism. In the past decades, several animal studies have investigated whether exercise has beneficial effects on BAT activity and recruitment. It was hypothesized that exercise could affect BAT function via the SNS, as exercise is known to increase general SNS activity (Wickler et al., 1987). However, most studies did not find any stimulatory effect of exercise on BAT activity (Scarpace et al., 1994; Segawa et al., 1998; Shibata and Nagasaka, 1987; Wickler et al., 1987), except for studies using swimming exercise protocols (Hirata, 1982a,b; Oh-ishi et al., 1996), which probably induced BAT activity to compensate for the heat loss to the water.

However, recent studies in rodents did observe stimulating effects of exercise on brown and beige adipocytes (Boström et al., 2012; Seebacher and Glanville, 2010; Slocum et al., 2012; Xu et al., 2011). A study in rats demonstrated that a low level of exercise training is beneficial for the metabolic response upon cold exposure in classical BAT (Seebacher and Glanville, 2010). It was shown that exercise in combination with cold exposure led to an increase in UCP-1 expression in BAT, whereas cold exposure $\left(12{ }^{\circ} \mathrm{C}\right)$ alone did not, suggesting that physical activity is required for an optimal heat producing BAT machinery. Xu et al. (2011) 
found that exercise in mice led to increased recruitment of adipogenic progenitor cells in interscapular BAT and increased UCP-1 expression ( $\sim$ twofold). Interestingly, in addition to these stimulating effects of exercise on classical BAT, they found an increased expression of the thermogenic gene program in epidydimal (visceral) adipose tissue, including increased UCP-1 levels ( $\sim$ twofold). Another study showed the occurrence of beige cells within the retroperitoneal depot (visceral) of rats already after 1 week of exercise (De Matteis et al., 2012). Quantification of UCP-1 positive adipocytes within the retriperitoneal WAT showed a 8-fold increase in the number of brown cells in the exercise group versus controls.

Interestingly, a recent study demonstrated that endurance exercise predominantly results in browning of subcutaneous WAT (Boström et al., 2012). In this study, Boström et al. found that mice overexpressing the transcriptional coactivator PGC1- $\alpha$ showed increased browning in inguinal WAT. Since exercise also increases PGC1- $\alpha$, they examined the effect of endurance exercise on markers of browning and observed similar effects. In further studies, they identified a new hormone called irisin, which is released by skeletal muscle after proteolysis of the membrane protein FNDC5. Boström et al. found that the irisin precursor FNDC5 induced browning in primary subcutaneous white adipocytes demonstrated by increased UCP1 mRNA (7-500-fold) and the upregulation of thermogenic genes (Ucp1, Elovl3, Cox7a1 and Otop1). Adenoviral-mediated overexpression of FNDC5 in mouse liver resulted in plasma irisin levels to be increased 3-4-fold, which increased UCP1 mRNA 13-fold in subcutaneous WAT. Furthermore, the same technique was used in C557BL/6 mice, which are prone to diet-induced obesity and diabetes, and increased irisin levels leading to improved glucose tolerance, decreased fasting insulin, increased oxygen consumption and reduced body weight. Together these results demonstrate the possible beneficial effects of endurance exercise on the recruitment of beige cells within subcutaneous white adipose tissue, and moreover, the potential of irisin to induce a more healthy metabolic phenotype.

Are these stimulating effects of exercise on the recruitment of beige cells translatable to humans? Importantly, the authors showed that irisin in mice and humans are $100 \%$ identical and that plasma irisin levels were increased twofold after 10 weeks of endurance training in human subjects (Boström et al., 2012). Interestingly, a study in patients with heart failure demonstrated increased FNDC5 expression in skeletal muscle in the patient group with a better aerobic performance (Lecker et al., 2012). Conversely, a recent study by Timmons et al. (2012) demonstrated that the stimulating effect of exercise on FNDC5 is limited. They analyzed FNDC5 induction by means of gene expression arrays in muscle biopsies from $\sim 200$ subjects from different exercise programs (both endurance and resistance straining) from earlier published studies. They found that endurance exercise ( 6 weeks of endurance cycling) in young adults as well as resistance training in 2080 year old men did not increase FNDC5 mRNA. However, only highly active elderly subjects did show increased (30\%) FNDC5 compared to sedentary controls. The authors therefore conclude that the stimulatory effect of exercise on irisin production is limited and that irisin probably has little contribution to the overall broad benefits of exercise on metabolic status.

Another recent paper on irisin presented data from cross-sectional and interventional studies on the physiological role of irisin in humans looking at correlations with anthropometric, metabolic, and hormonal parameters (Huh et al., 2012). The presence of FNDC5 in human tissues, in skeletal muscle but also in the pericardium, intracranial artery, and rectum (cardiac and smooth muscles) was confirmed and muscle mass was found to be the primary predictor of circulating irisin in humans. However no support for a beneficial role for irisin in metabolic regulation in a cross sectional study of 117 middle-aged women (BMI range $20-47.7 \mathrm{~kg} /$ $\mathrm{m}^{2}$ ) was found. Interestingly, acute anaerobic exercise (sprint exercise) in young healthy subjects increased irisin levels, whereas chronic exercise of 8 weeks (three times sprint exercise per week) did not. It is important to note that this study solely looked at anaerobic exercise; it is known that aerobic exercise increases PGC1 $\alpha$ to a greater extent than anaerobic exercise (Handschin and Spiegelman, 2008), and this (aerobic) type of exercise would thus be more effective in irisin production.

These first human studies question the potential beneficial effects of irisin on metabolic status. However, prospective studies that measure the direct effects of exercise on browning are required, and prospective studies should focus on aerobic exercise protocols. In addition to the physiological release of irisin by exercise, the therapeutic use of irisin in human clinical trials should be investigated.

\subsection{Natriuretic peptides and brown adipose tissue}

A recent study showed that the cardiac natriuretic peptides (NPs) are capable of browning white adipocytes from mice and humans (Bordicchia et al., 2012). The cardiac peptides, atrial NP (ANP) and the ventricular form (BNP), are predominantly known for their role in the homeostatic control of blood pressure, by promoting vasodilatation, natriuresis and diuresis, and inhibiting renin and aldosterone release (Levin et al., 1998). Later, these hormones were also found to regulate lipolysis as demonstrated both in vitro as in vivo (Sengenès et al., 2000). Natriuretic peptides mediate these lipolytic effects predominantly via the NP receptor A (NPRA), whereas the clearance receptor (NPRC) removes the peptides from the circulation. Binding of the NPs to the guanylyl cyclase receptor NPRA leads to increased cellular cGMP, which stimulates lipolysis by acting on HSL (Sengenès et al., 2000). These lipolytic effects of the NPs were only observed in human WAT, and were thought to be primate specific due to the high expression of clearance receptors and a low expression of "biologically active" receptors in other species (Sengenès et al., 2002).

This was confirmed in the study by Bordicchia et al. (2012), in which primary adipocyte cultures from wildtype mice showed no lipolytic response upon ANP infusion. However, in NPRC knockout mice they did find increased lipolysis in these adipocytes, indicating the inhibitory effects of this clearance receptor. Interestingly, these knockout mice had reduced adipose tissue mass and a more brownish adipose tissue phenotype. In support, brown adipocyte marker genes, such as PRDM16, were elevated in both BAT and WAT (inguinal and epididymal). These results indicated the browning effects on WAT via the NPs. It was then shown that exposing mice to cold ( $4^{\circ}$ for $6 \mathrm{~h}$ ) significantly increased plasma BNP levels, and ANP and BNP mRNA expression in the heart. Furthermore, BNP infusion in mice increased UCP- 1 and PGC- $1 \alpha$ mRNA expression in both WAT and BAT (Bordicchia et al., 2012). Altogether, these data demonstrate that the NPs have the capacity to enhance BAT activity and recruitment in mice in vitro and in vivo.

Do these NPs exert similar effects in humans? Administering ANP systemically and via a microdialysis probe increased lipolysis in healthy men (Birkenfeld et al., 2005). One functional role for the lipolytic effects of NPs could be substrate supply of fatty acids to the heart and muscle during aerobic exercise (Moro et al., 2006). In addition, it is thought that the NPs are important regulators in postprandial fatty acid oxidation in humans (Birkenfeld et al., 2008). Interestingly, it is known in humans that low NP levels are associated with hypertension, obesity, insulin resistance and diabetes (Khan et al., 2011; Magnusson et al., 2012). Furthermore, weight loss in obese subjects by lifestyle intervention (ChainaniWu et al., 2010) and bariatric surgery (Changchien et al., 2011; Chen-Tournoux et al., 2010; St Peter et al., 2006) showed that 
BNP levels are increased after weight loss. Interestingly patients with heart failure who suffer from severe weight loss (cachexia) have increased levels of both forms of NPs (de Lemos et al., 2003; Tikkanen et al., 1985), and elevated energy expenditure levels, and it could be suggested that elevated NP levels increase brown adipocyte recruitment and activity leading to elevated EE. Birkenfeld et al. $(2005,2008)$ showed that ANP infusion increased postprandial energy expenditure, however energy expenditure in the fasted state was not affected. The dosage $(25 \mathrm{ng} / \mathrm{kg} / \mathrm{min})$ of ANP used by Birkenfeld et al. (2008) increased plasma ANP concentrations fourfold (approximately $300 \mathrm{pg} / \mathrm{mL}$ ), which is lower than found in heart failure patients ( $>500 \mathrm{pg} / \mathrm{mL}$ ). This relative low dose already affected lipid mobilization and postprandial thermogenesis (and possibly BAT) without causing any adverse effects. Currently, therapeutic use of NPs (carperitide and nesiritide) in patients with acute heart failure and acutely decompensated heart failure is only possible by means of infusion and not orally (Saito, 2010).

The potential effect of NPs on browning in humans has been demonstrated in the study of Bordicchia et al., where they tested whether NPs could induce a thermogenic gene program in differentiated human multipotent adipose-derived stem (hMADS) cells and subcutaneous adipocytes. Interestingly, both ANP and BNP activated PGC- $1 \alpha$ and UCP-1 expression, induced mitochondrial biogenesis, and increased uncoupled and total respiration. These findings imply the potential role of the NPs in increasing acute thermogenesis and brown adipocyte recruitment in humans. They demonstrated that the mechanism of action of the NP's share a common downstream target with the adrenergic pathway, namely p38 MAPK. Activation of the p38 MAPK pathway ultimately leads to increased transcription of UCP-1 and PGC- $1 \alpha$ (Bordicchia et al., 2012). Moreover, it was shown that ANP treatment of hMADS led to a similar increase in UCP-1, PGC- $1 \alpha$, and cytochrome c protein levels as shown during $\beta$-adrenergic treatment. The authors also found that both the adrenergic and NP's signaling pathways work additive at very low (physiological) concentrations. The activation pathway of the NPs could therefore play a prominent role in addition to the well-known adrenergic pathway in inducing both shortterm as long-term effects on BAT. Currently, this is the only direct evidence of browning effects via NPs in humans and future studies are warranted.

\section{Conclusions and perspectives}

The current global obesity problem is affecting more than 1.4 billion adults of 20 years and older, and strikingly, more than 40 million children under the age of five were overweight in 2010 (WHO). Obesity goes along with increased risk on developing diseases such as type 2 diabetes and cardiovascular diseases. Finding strategies to induce weight loss are therefore necessary. Currently, brown adipose tissue is regarded as a potential tissue to tackle obesity due to its great capacity to increase energy expenditure and thereby stimulating weight loss. The rediscovery of functional BAT in humans has resulted in an explosion of BAT studies, especially in rodents, to find potential molecules that could lead to BAT hypertrophy and hyperplasia. It is now clear that a third type of adipocyte exists, the beige adipocyte, which can be recruited within WAT after cold acclimation and long-term adrenergic receptor stimulation. This distinct type of adipocyte has shown to arise from a different lineage as the other two types, although functionally and metabolically seen it is similar to the brown adipocyte. Current evidence shows that human BAT is likely composed of mainly beige adipocytes.

Prospective studies in humans are scarce, mostly because of the difficulties associated with the technique to measure BAT activity (PET-CT). Nevertheless, current studies have shown that cold expo- sure is the most effective in stimulating BAT in humans. Adjusting ambient temperature in public buildings to the lower range of our thermoneutral zone could therefore be a sensible and physiological way to increase thermogenesis by increasing the thermogenic potential of BAT. Adrenergic agonists (isoprenaline and ephedrine) have not shown to be effective in BAT activation as high dosages are required. This indicates that pharmacological activation of BAT via the adrenergic part of the SNS is difficult. Furthermore, a major drawback of adrenergic agonists and sympathomimetics is the associated cardiovascular stress. Sympathetic activation via capsinoids could be a way to increase energy expenditure and possibly weight loss (with low risks of adverse events), and the indirect evidence of BAT being a mediator is promising. Insulin has been shown to induce glucose uptake in BAT to higher levels than WAT, and comparable to skeletal muscle. However, since perfusion of BAT was absent, it remains unclear whether actual thermogenesis takes place after insulin stimulation.

Interestingly, studies in rodents have shown additional pathways to activate BAT and recruit beige adipocytes. Two of them - irisin and NPs - have recently attracted much attention, but definitive answers in humans are so far lacking. Therefore, the coming years are crucial in finding and testing novel activators of BAT in human clinical trials, but most of all to test the hypothesis that activation of BAT may indeed be of importance in the treatment of human obesity. Furthermore, future studies should also reveal if continuous activation of mitochondrial uncoupling in BAT could lead to hyperthermia, as has previously been shown to occur when dinitrophenol was used in humans to obtain weight loss.

\section{Acknowledgements}

We would like to thank Boudewijn Brans for his helpful suggestions and Anouk van der Lans for providing the PET-CT image.

\section{References}

al-Adsani, H., Hoffer, L., Silva, J., 1997. Resting energy expenditure is sensitive to small dose changes in patients on chronic thyroid hormone replacement. J. Clin. Endocrinol. Metab. 82, 1118-1125.

Bartelt, A., Bruns, O.T., Reimer, R., Hohenberg, H., Ittrich, H., Peldschus, K., Kaul, M.G., Tromsdorf, U.I., Weller, H., Waurisch, C., Eychmüller, A., Gordts, P.L., Rinninger F., Bruegelmann, K., Freund, B., Nielsen, P., Merkel, M., Heeren, J., 2011. Brown adipose tissue activity controls triglyceride clearance. Nat. Med. 17, 200-205.

Birkenfeld, A., Boschmann, M., Moro, C., Adams, F., Heusser, K., Franke, G., Berlan, M. Luft, F., Lafontan, M., Jordan, J., 2005. Lipid mobilization with physiological atrial natriuretic peptide concentrations in humans. J. Clin. Endocrinol. Metab. 90 3622-3628.

Birkenfeld, A., Budziarek, P., Boschmann, M., Moro, C., Adams, F., Franke, G., Berlan, M., Marques, M., Sweep, F., Luft, F., Lafontan, M., Jordan, J., 2008. Atrial natriuretic peptide induces postprandial lipid oxidation in humans. Diabetes 57, 3199-3204.

Bordicchia, M., Liu, D., Amri, E.-Z., Ailhaud, G., Dessì-Fulgheri, P., Zhang, C., Takahashi, N., Sarzani, R., Collins, S., 2012. Cardiac natriuretic peptides act via p38 MAPK to induce the brown fat thermogenic program in mouse and human adipocytes. J. Clin. Invest. 122, 1022-1036.

Boström, P., Wu, J., Jedrychowski, M., Korde, A., Ye, L., Lo, J., Rasbach, K., Boström, E. Choi, J., Long, J., Kajimura, S., Zingaretti, M.C., Vind, B.F., Tu, H., Cinti, S., Højlund, K., Gygi, S.P., Spiegelman, B.M., 2012. A PGC1- $\alpha$-dependent myokine that drives brown-fat-like development of white fat and thermogenesis. Nature 481, 463468.

Cannon, B., Nedergaard, J., 2004. Brown adipose tissue: function and physiological significance. Physiol. Rev. 84, 277-359.

Carey, A.L., Formosa, M.F., Van Every, B., Bertovic, D., Eikelis, N., Labert, G.W., Kalff V., Duffy, S.J., Cherk, M.H., Kingwell, B.A., 2013. Ephedrine activates brown adipose tissue in lean but not obese humans. Diabetologia 56, 147-155.

Chainani-Wu, N., Weidner, G., Purnell, D., Frenda, S., Merritt-Worden, T., Kemp, C., Kersh, E., Ornish, D., 2010. Relation of B-type natriuretic peptide levels to body mass index after comprehensive lifestyle changes. Am. J. Cardiol. 105, 15701576.

Changchien, E., Ahmed, S., Betti, F., Higa, J., Kiely, K., Hernandez-Boussard, T., Morton, J., 2011. B-type natriuretic peptide increases after gastric bypass surgery and correlates with weight loss. Surg. Endosc. 25, 2338-2343.

Chen-Tournoux, A., Khan, A., Baggish, A., Castro, V., Semigran, M., McCabe, E., Moukarbel, G., Reingold, J., Durrani, S., Lewis, G., Newton-Cheh, C., Scherrer- 
Crosbie, Kaplan, L.M., Wang, T.J., 2010. Effect of weight loss after weight loss surgery on plasma N-terminal pro-B-type natriuretic peptide levels. Am. J. Cardiol. 106, 1450-1455.

Christiansen, E., Garby, L., 2002. Prediction of body weight changes caused by changes in energy balance. Eur. J. Clin. Invest. 32, 826-830.

Cinti, S., 2001. The adipose organ: morphological perspectives of adipose tissues. Proc. Nutr. Soc. 60, 319-328.

Cinti, S., 2002. Adipocyte differentiation and transdifferentiation: Plasticity of the adipose organ. J. Endicrinol. Invest. 25, 823-825.

Cypess, A.M., Lehman, S., Williams, G., Tal, I., Rodman, D., Goldfine, A.B., Kuo, F.C. Palmer, E.L., Tseng, Y.H., Doria, A., Kolodny, G.M., Kahn, C.R., 2009. Identification and importance of brown adipose tissue in adult humans. N. Engl. J. Med. 360 1509-1517.

Cypess, A.M., Chen, Y.C., Sze, C., Wang, K., English, J., Chan, O., Holman, A.R., Tal, I., Palmer, M.R., Kolodny, G.M., Kahn, C.R., 2012. Cold but not sympathomimetics activates human brown adipose tissue in vivo. Proc. Natl. Acad. Sci. USA 109 10001-10005.

Davis, T., 1961. Chamber cold acclimatization in man. J. Appl. Physiol. 16, 10111015.

de Lemos, J., McGuire, D., Drazner, M., 2003. B-type natriuretic peptide in cardiovascular disease. Lancet 362, 316-322.

De Matteis, R., Lucertini, F., Guescini, M., Polidori, E., Zeppa, S., Stocchi, V., Cinti, S. Cuppini, R., 2012. Exercise as a new physiological stimulus for brown adipose tissue activity. Nutr. Metab. Cardiovac. Dis. (Epub ahead of print).

Feldmann, H.M., Golozoubova, V., Cannon, B., Nedergaard, J., 2009. UCP1 ablation induces obesity and abolishes diet-induced thermogenesis in mice exempt from thermal stress by living at thermoneutrality. Cell Metab. 9, 203-209.

Frontini, A., Cinti, S., 2010. Distribution and development of brown adipocytes in the murine and human adipose organ. Cell Metab. 11, 253-256.

Galgani, J., Ravussin, E., 2010. Effect of dihydrocapsiate on testing metabolic rate in humans. Am. J. Clin. Nutr. 92, 1089-1093.

Guerra, C., Navarro, P., Valverde, A., Arribas, M., Brüning, J., Kozak, L., Kahn, C., Benito, M., 2001. Brown adipose tissue-specific insulin receptor knockout shows diabetic phenotype without insulin resistance. J. Clin. Invest. 108, 1205 1213.

Gunawardana, S.C., Piston, D.W., 2012. Reversal of type 1 diabetes in mice by brown adipose tissue transplant. Diabetes 61, 674-682.

Hadi, M., Chen, C., Whatley, M., Pacak, K., Carrasquillo, J., 2007. Brown fat imaging with (18)F-6-fluorodopamine PET/CT, (18)F-FDG PET/CT, and (123)I-MIBG SPECT: a study of patients being evaluated for pheochromocytoma. J. Nucl. Med. 48, 1077-1083.

Handschin, C., Spiegelman, B., 2008. The role of exercise and PGC1alpha in inflammation and chronic disease. Nature 454, 463-469.

Heaton, J., 1972. The distribution of brown adipose tissue in the human. J. Anat. 112, 35-39.

Hirata, K., 1982a. Blood flow to brown adipose tissue and norepinephrine-induced calorigenesis in physically trained rats. Jpn. J. Physiol. 32, 279-291.

Hirata, K., 1982b. Enhanced calorigenesis in brown adipose tissue in physically trained rats. Jpn. J. Physiol. 32, 647-653.

Huh, J., Panagiotou, G., Mougios, V., Brinkoetter, M., Vamvini, M., Schneider, B. Mantzoros, C., 2012. FNDC5 and irisin in humans: I. Predictors of circulating concentrations in serum and plasma and II. mRNA expression and circulating concentrations in response to weight loss and exercise. Metabolism 61, 17251738.

Joshi, P., Lele, V., 2012. Unexpected visitor on FDG PET/CT-Brown Adipose Tissue (BAT) in mesentery in a case of retroperitoneal extra-adrenal pheochromocytoma: is the BAT activation secondary to catecholaminesecreting pheochromocytoma? Clin. Nucl. Med. 37, 20.

Kawabata, F., Inoue, N., Masamoto, Y., Matsumura, S., Kimura, W., Kadowaki, M. Higashi, T., Tominaga, M., Inoue, K., Fushiki, T., 2009. Non-pungent capsaicin analogs (capsinoids) increase metabolic rate and enhance thermogenesis via gastrointestinal TRPV1 in mice. Biosci. Biotechnol. Biochem. 73, 2690-2697.

Khan, A., Cheng, S., Magnusson, M., Larson, M., Newton-Cheh, C., McCabe, E., Coviello, A., Florez, J., Fox, C., Levy, D., Robins, S.J., Arora, P., Bhasin, S., Lam, C.S., Vasan, R.S., Melander, O., Wang, T.J., 2011. Cardiac natriuretic peptides, obesity, and insulin resistance: evidence from two community-based studies. J. Clin. Endocrinol. Metab. 96, 3242-3249.

Kuji, I., Imabayashi, E., Minagawa, A., Matsuda, H., Miyauchi, T., 2008. Brown adipose tissue demonstrating intense FDG uptake in a patient with mediastinal pheochromocytoma. Ann. Nucl. Med. 22, 231-235.

Lebon, V., 2001. Effect of triiodothyronine on mitochondrial energy coupling in human skeletal muscle. J. Clin. Invest. 108

Lebron, L., Chou, A., Carrasquillo, J., 2010. Interesting image. Unilateral F-18 FDG uptake in the neck, in patients with sympathetic denervation. Clin. Nucl. Med. 35, 899-901.

Lecker, S., Zavin, A., Cao, P., Arena, R., Allsup, K., Daniels, K., Joseph, J., Schulze, P. Forman, D., 2012. Expression of the irisin precursor FNDC5 in skeletal muscle correlates with aerobic exercise performance in patients with heart failure. Circ. Heart. Fail. 5, 812-818.

Levin, E., Gardner, D., Samson, W., 1998. Natriuretic peptides. N. Engl. J. Med. 339 321-328.

Lowell, B.B., Spiegelman, B.M., 2000. Towards a molecular understanding of adaptive thermogenesis. Nature 404, 652-660.

Magnusson, M., Jujic, A., Hedblad, B., Engström, G., Persson, M., Struck, J., Morgenthaler, N., Nilsson, P., Newton-Cheh, C., Wang, T., Melander, O., 2012. Low plasma level of atrial natriuretic peptide predicts development of diabetes: the prospective Malmo Diet and Cancer study. J. Clin. Endocrinol. Metab. 97. 638-645.

Mitchell, C., Savage, D., Dufour, S., Schoenmakers, N., Murgatroyd, P., Befroy, D., Halsall, D., Northcott, S., Raymond-Barker, P., Curran, S., Henning, E., Keogh, J., Owen, P., Lazarus, J., Rothman, D.L., Farooqi, I.S., Shulman, G.I., Chatterjee, K., Petersen, K.F., 2010. Resistance to thyroid hormone is associated with raised energy expenditure, muscle mitochondrial uncoupling, and hyperphagia. J. Clin. Invest. 120, 1345-1354.

Moro, C., Polak, J., Hejnova, J., Klimcakova, E., Crampes, F., Stich, V., Lafontan, M., Berlan, M., 2006. Atrial natriuretic peptide stimulates lipid mobilization during repeated bouts of endurance exercise. Am. J. Physiol. Endocrinol. Met. 290, E864-869.

Oh-ishi, S., Kizaki, T., Toshinai, K., Haga, S., Fukuda, K., Nagata, N., Ohno, H., 1996. Swimming training improves brown-adipose-tissue activity in young and old mice. Mech. Ageing Dev. 89, 67-78.

Ono, K., Tsukamoto-Yasui, M., Hara-Kimura, Y., Inoue, N., Nogusa, Y., Okabe, Y., Nagashima, K., Kato, F., 2011. Intragastric administration of capsiate, a transient receptor potential channel agonist, triggers thermogenic sympathetic responses. J. Appl. Physiol. 110, 789-798.

Orava, J., Nuutila, P., Lidell, M., Oikonen, V., Noponen, T., Viljanen, T., Scheinin, M., Taittonen, M., Niemi, T., Enerbäck, S., Virtanen, K.A., 2011. Different metabolic responses of human brown adipose tissue to activation by cold and insulin. Cell Metab. 14, 272-279.

Ouellet, V., Labbé, S., Blondin, D., Phoenix, S., Guérin, B., Haman, F., Turcotte, E., Richard, D., Carpentier, A., 2012. Brown adipose tissue oxidative metabolism contributes to energy expenditure during acute cold exposure in humans. J. Clin. Invest. 122, 545-552.

Parysow, O., Mollerach, A.M., Jager, V., Racioppi, S., San Roman, J., Gerbaudo, V.H., 2007. Low-dose oral propranolol could reduce brown adipose tissue F-18 FDG uptake in patients undergoing PET scans. Clin. Nucl. Med. 32, 351-357.

Petrovic, N., Walden, T., Shabalina, I., Timmons, J., Cannon, B., Nedergaard, J., 2010. Chronic peroxisome proliferator-activated receptor gamma (PPARgamma) activation of epididymally derived white adipocyte cultures reveals a population of thermogenically competent, UCP1-containing adipocytes molecularly distinct from classic brown adipocytes. J. Biol. Chem. 285, 71537164.

Saito, Y., 2010. Roles of atrial natriuretic peptide and its therapeutic use. J. Cardiol. $56,262-270$.

Saito, M., Okamatsu-Ogura, Y., Matsushita, M., Watanabe, K., Yoneshiro, T., NioKobayashi, J., Iwanaga, T., Miyagawa, M., Kameya, T., Nakada, K., Kawai, Y., Tsujisaki, M., 2009. High incidence of metabolically active brown adipose tissue in healthy adult humans: effects of cold exposure and adiposity. Diabetes 58, 1526-1531.

Scarpace, P., Yenice, S., Tümer, N., 1994. Influence of exercise training and age on uncoupling protein mRNA expression in brown adipose tissue. Pharmacol. Biochem. Behav. 49, 1057-1105.

Seebacher, F., Glanville, E., 2010. Low levels of physical activity increase metabolic responsiveness to cold in a rat (Rattus fuscipes). PLoS ONE 5, e13022.

Segawa, M., Oh-Ishi, S., Kizaki, T., Ookawara, T., Sakurai, T., Izawa, T., Nagasawa, J., Kawada, T., Fushiki, T., Ohno, H., 1998. Effect of running training on brown adipose tissue activity in rats: a reevaluation. Res. Commun. Mol. Pathol. Pharmacol. 100, 77-82.

Sengenès, C., Berlan, M., De Glisezinski, I., Lafontan, M., Galitzky, J., 2000. Natriuretic peptides: a new lipolytic pathway in human adipocytes. FASEB J. 14, 13451351.

Sengenès, C., Zakaroff-Girard, A., Moulin, A., Berlan, M., Bouloumié, A., Lafontan, M., Galitzky, J., 2002. Natriuretic peptide-dependent lipolysis in fat cells is a primate specificity. Am. J. Physiol. Regul. Integr. Comp. Physiol. 283, R257-265.

Sharp, L., Shinoda, K., Ohno, H., Scheel, D., Tomoda, E., Ruiz, L., Hu, H., Wang, L., Pavlova, Z., Gilsanz, V., Kajimura, S., 2012. Human BAT possesses molecular signatures that resemble beige/brite cells. PLoS ONE 7, e49452.

Shibata, H., Nagasaka, T., 1987. The effect of forced running on heat production in brown adipose tissue in rats. Physiol. Behav. 39, 377-380.

Silva, J., 2006. Thermogenic mechanisms and their hormonal regulation. Physiol. Rev. 86, 435-464.

Slocum, N., Durrant, J., Bailey, D., Yoon, L., Jordan, H., Barton, J., Brown, R., Clifton, L., Milliken, T., Harrington, W., Kimbrough, C., Faber, C.A., Cariello, N., Elangbam, C.S., 2012. Responses of brown adipose tissue to diet-induced obesity, exercise, dietary restriction and ephedrine treatment. Exp. Toxicol. Pathol. (Epub ahead of print).

Soderlund, V., Larsson, S.A., Jacobsson, H., 2007. Reduction of FDG uptake in brown adipose tissue in clinical patients by a single dose of propranolol. Eur. J. Nucl. Med. Mol. Imaging 34, 1018-1022.

St Peter, J., Hartley, G., Murakami, M., Apple, F., 2006. B-type natriuretic peptide (BNP) and N-terminal pro-BNP in obese patients without heart failure: relationship to body mass index and gastric bypass surgery. Clin. Chem. 52 , 680-685.

Tikkanen, I., Fyhrquist, F., Metsärinne, K., Leidenius, R., 1985. Plasma atrial natriuretic peptide in cardiac disease and during infusion in healthy volunteers. Lancet 2, 66-69.

Timmons, J.A., Baar, K., Davidsen, P.K., Atherton, P.J., 2012. Is irisin a human exercise gene? Nature 480, E9-10.

van Marken Lichtenbelt, W., Schrauwen, P., 2011. Implications of nonshivering thermogenesis for energy balance regulation in humans. Am. J. Physiol. Regul. Integr. Comp. Physiol. 301, 96. 
van Marken Lichtenbelt, W.D., Vanhommerig, J.W., Smulders, N.M., Drossaerts, J.M., Kemerink, G.J., Bouvy, N.D., Schrauwen, P., Teule, G.J., 2009. Cold-activated brown adipose tissue in healthy men. N. Engl. J. Med. 360, 1500-1508.

Vijgen, G.H., Bouvy, N.D., Teule, G.J., Brans, B., Schrauwen, P., van Marken Lichtenbelt, W.D., 2011. Brown adipose tissue in morbidly obese subjects. PLoS ONE 6, e17247.

Vijgen, G., Bouvy, N., Teule, G.J., Brans, B., Hoeks, J., Schrauwen, P., van Marken Lichtenbelt, W., 2012. Increase in brown adipose tissue activity after weight loss in morbidly obese subjects. J. Clin. Endocrinol. Metab. 97, E1229-1233.

Virtanen, K.A., Lidell, M.E., Orava, J., Heglind, M., Westergren, R., Niemi, T., Taittonen, M., Laine, J., Savisto, N.J., Enerback, S., Nuutila, P., 2009. Functional brown adipose tissue in healthy adults. N. Engl. J. Med. 360, 1518-1525.

Vosselman, M.J., van der Lans, A.A., Brans, B., Wierts, R., van Baak, M.A., Schrauwen, P., Lichtenbelt, W.D., 2012. Systemic $\beta$-adrenergic stimulation of thermogenesis is not accompanied by brown adipose tissue activity in humans. Diabetes 61, $3106-3113$.

Waldén, T., Hansen, I., Timmons, J., Cannon, B., Nedergaard, J., 2012. Recruited vs. nonrecruited molecular signatures of brown, "brite", and white adipose tissues. Am. J. Physiol. Endocrinol. Metab. 302, E19-31.

Whiting, S., Derbyshire, E., Tiwari, B., 2012. Capsaicinoids and capsinoids. A potential role for weight management? A systematic review of the evidence. Appetite 59, 341-348.

Whittle, A.J., 2012. Searching for ways to switch on brown fat: are we getting warmer? J. Mol. Endocrinol. 49, 79-87.

Whittle, A.J., Vidal-Puig, A., 2012. NPs - heart hormones that regulate brown fat? J. Clin. Invest. 122, 804-807.

Wickler, S., Stern, J., Glick, Z., Horwitz, B., 1987. Thermogenic capacity and brown fat in rats exercise-trained by running. Metabolism 36, 76-81.
Wu, J., Boström, P., Sparks, L., Ye, L., Choi, J., Giang, A.-H., Khandekar, M., Virtanen, K., Nuutila, P., Schaart, G., Huang, K., Tu, H., van Marken Lichtenbelt, W.D., Hoeks, J. Enerbäck, S., Schrauwen, P., Spiegelman, B.M., 2012. Beige adipocytes are a distinct type of thermogenic fat cell in mouse and human. Cell 150, 366-376.

Xu, X, Ying Z, Cai, M., Xu, Z, Li, Y. Jiang S., Tzan, K., Wang, A, Parthasarathy, S., He, G., Rajagopalan, S., Sun, Q., 2011. Exercise ameliorates high-fat diet-induced metabolic and vascular dysfunction, and increases adipocyte progenitor cell population in brown adipose tissue. Am. J. Physiol. Regul. Integr. Comp. Physiol. 300, R1115-R1125.

Yamaga, L., Thom, A., Wagner, J., Baroni, R., Hidal, J., Funari, M., 2008. The effect of catecholamines on the glucose uptake in brown adipose tissue demonstrated by (18)F-FDG PET/CT in a patient with adrenal pheochromocytoma. Eur. J. Nucl. Med. Mol. Imaging 35, 446-447.

Yoneshiro, T., Aita, S., Matsushita, M., Kameya, T., Nakada, K., Kawai, Y., Saito, M. 2011. Brown adipose tissue, whole-body energy expenditure, and thermogenesis in healthy adult men. Obesity (Silver Spring) 19, 13-16.

Yoneshiro, T., Aita, S., Kawai, Y., Iwanaga, T., Saito, M., 2012. Nonpungent capsaicin analogs (capsinoids) increase energy expenditure through the activation of brown adipose tissue in humans. Am. J. Clin. Nutr. 95, 845-850.

Young, P., Arch, J., Ashwell, M., 1984. Brown adipose tissue in the parametrial fat pad of the mouse. FEBS Lett. 167, 10-14.

Zingaretti, M.C., Crosta, F., Vitali, A., Guerrieri, M., Frontini, A., Cannon, B. Nedergaard, J., Cinti, S., 2009. The presence of UCP1 demonstrates that metabolically active adipose tissue in the neck of adult humans truly represents brown adipose tissue. FASEB J. 23, 3113-3120. 